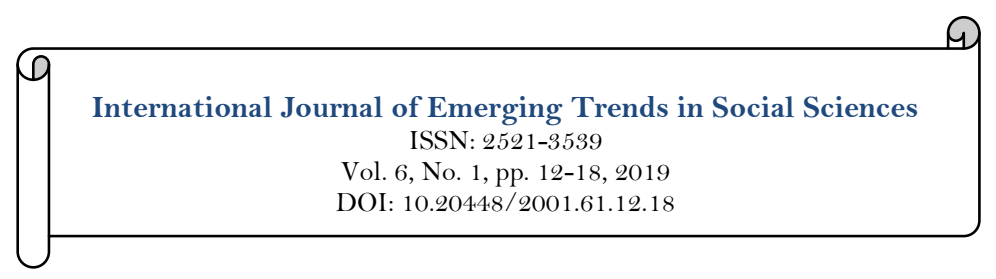

Updates

\title{
Research on the Application of Value Creation of Big Data in Smart Tourism
}

\author{
Yu Zhao's \\ Yanqing Zhan $^{2}$ \\ 1, Jiangxi Normal University, Management Science and Engineering Research Center, Nanchang, Jiangxi Province, China \\ ${ }^{2}$ Email:18296138355@163.com
}

\begin{tabular}{l|l}
\multicolumn{3}{|c}{ Abstract } & \\
Against the background of the new era, the rapid progress of information & Keywords: \\
science and technology represented by big data, cloud computing and Internet & New era \\
of things promotes the intelligent transformation of tourism industry. Based & Big data \\
on the technical support of big data, it integrates tourism resources to & Smart tourism \\
generate value creation and apply it in smart tourism, and promotes the & Tourism development. \\
optimization and innovation of tourism at the level of marketing, service & Licensed: \\
and management. In the context of informatization, the implementation of & This work is licensed under a \\
smart tourism has become the only rway for the development of the tourism & Creative Commons Attribution 4.0 \\
industry (Dai, 2015). However, the application of big data in smart tourism & License. \\
also faces such problems as dense and miscellaneous information data, & Publisher: \\
uneven level of information technology, lack of smart tourism big data & Scientific Publishing Institute \\
professionals, and privacy data security (Yang, 2015). This paper discusses & Accepted: 25 July 2019 \\
the development status and future direction of smart tourism in the context of & Published: 6 August 2019 \\
big data, so as to boost the steady development of smart tourism relying on & \\
big data platform. &
\end{tabular}

Funding: This study received no specific financial support.

Competing Interests: Both authors contributed equally to the conception and design of the study.

\section{Introduction}

In the report of the 19th national congress of the communist party of China (CPC), it was proposed to "promote the deep integration of the Internet, big data, artificial intelligence and real economy" (Xing, 2019). In the context of big data, it was advocated that the implementation of smart tourism is a new task to promote the development of tourism in line with The Times. The core of smart tourism is to enable tourists to have better experience and feelings, so that tourists can efficiently and conveniently obtain the required tourism information and enjoy more intelligent and personalized tourism services (Chen, 2015).

Big data affects all levels of smart tourism industry, and the management and operation mode of the entire tourism industry will change with emerging technologies. At present, the application of big data in the field of smart tourism in China has a relatively short development time, and there is no rich experience in the construction and management development of smart tourism. Most of the tourism industry in China has a low penetration rate of big data technology, and the application research of big data technology is still very simple. The smart tourism industry does not fully use the tool of big data analysis and processing, so it cannot drive the potential tourism consumption demand, and the smart tourism cannot get further development.

Against this background, more and more people devote their time and energy to study the integration and development of big data and smart tourism. The construction of smart tourism relying on big data platform is full of opportunities and challenges. How to better integrate big data technology and smart tourism industry still needs to be explored in practice. 


\section{Application of Big Data in Smart Tourism}

\subsection{What is Smart Tourism}

Smart tourism is a new proposition developed from the "smart earth" proposed by IBM and the "smart city" practiced in China (Guo \& Li, 2015). China put forward the concept of "smart tourism" in 2010. Wisdom tourism is through the use of big data, cloud computing, Internet of things, such as network information processing technique is applied to tourism industry service system, management system, marketing system, such as system, visitors through the use of mobile terminal equipment can convenient self-service tourist destination basic information, the real-time trend of tourism, tourist activities and tourism related information such as messages, the mobile terminal of the Internet with the successful implementation of tourists real-time interaction. With the widespread popularization of social media, the rapid dissemination of tourism information and the high-speed flow of tourists, smart tourism is undoubtedly a unique step in the development of tourism information and communication technology. Smart tourism involves multiple components of tourism communication technology: smart scenic spot, smart tourism experience and smart business (Xie, 2017).

First,Smart scenic spot. Smart scenic spot refers to the tourist scenic spot operators can use the intelligent system to real-time monitoring and management of the geographical resource status of the scenic spot, the trend of tourists, the whereabouts of staff, and the basic service facilities of the scenic spot, so as to fully grasp the trend of the scenic spot and realize convenient and intelligent visualization of comprehensive management and service (Wu, 2015).

Second, travel experience. Smart tourism experience focuses more on the tourism experience brought by information technology, and enhances its function through personalization, situational awareness and realtime monitoring. Rapid and comprehensive identification of information, more efficient connectivity and realtime synchronization are the main influencing factors of smart tourism experience.

Third, smart business. Smart business refers to the complex business ecosystem that creates and supports tourism resource exchange and tourism experience ( $\mathrm{Tu} \& \mathrm{Liu}, 2014$ ). Buhalis and Amaranggana describe several characteristics of the business components of smart tourism, including dynamic interconnection of stakeholders, digitization of core business processes and organizational agility.

\subsection{Application of Big Data}

IBM puts forward five characteristics of big data: large amount of data, complex and diverse data types, high-speed transmission, low value density and authenticity. Big data is a complex and complex data collection formed under the development and popularization of modern network information technology. The year 2013 is the first year of big data, which marks that big data technology will be deeply applied to all walks of life, generating great revolutionary power. It is of great significance to introduce big data analysis technology into the construction of smart tourism industry to promote the economic development of tourism industry (Jiang \& Chen, 2018). Nowadays, tourism is an industry that covers multiple fields and has a large amount of data information. Tourism is "food, accommodation, travel, travel, shopping and entertainment". Each activity will generate a large amount of tourism information data. Big data technology can conduct mining, analysis and processing of these data sets, and valuable data analysis results will provide reference decision-making opinions for tourism industry operators and tourism management organizations. In order to ensure that smart tourism industry can be supported by information technology, it is required to set up corresponding tourism big data platform.

The development of tourism industry is increasingly inseparable from network information technology, especially the accurate docking of relevant information of its tourism website needs the support of big data technology, so as to make recommendations on appropriate tourism projects for better choices and better services for tourists. Make use of relevant data records, classify and summarize information data, strengthen communication and cooperation with offline tourism industry, and vigorously promote the rapid development of tourism. Under the big data in the information age today, visitors need only through the website, can to search information they want, and website will popup corresponding according to its search keywords to eat, drink, play, live, line, such as travel required, at the same time to choose products, tourism information rich variety, general need your judgment. In addition, the big data technology used in smart tourism generally relies on the data classification and integration function of search engine. The integration of such data can not only enable tourism companies to explore potential tourism customers, but also provide powerful help to the monitoring of the current group situation of the tourism industry and the observation of personnel flow in scenic spots.

Big data plays a role of technical support and guarantee in smart tourism industry, which conforms to the trend of big data era. Smart tourism is a new stage of intelligent and informationized development of tourism industry, which also conforms to the future development direction of combining big data and tourism industry (Wang, 2014). 


\subsection{The Fit between Big Data and Smart Tourism}

2.3.1. Big Data and Smart Tourism Services

Smart tourism services are mainly divided into online and offline services. Online services mainly include the search and consultation of tourism information, online ordering of tourism products, feedback and evaluation, and after-sales services. Offline services mainly include intelligent travel, intelligent language orientation, intelligent tour guide, self-service tour guide and explanation service.

\section{Online Smart Travel Service}

The most basic function of the tourism service platform is to provide tourists with the search and consultation service of tourism information. With the help of mobile phones, computers or other mobile terminals, tourists can search and inquire the relevant information of target tourist destinations on the specialized tourism service platform to reasonably plan the tourism route. In addition, the tourism service platform also can be one-stop services for tourists, visitors can directly online through their various website platform order size enough traffic tickets, hotel accommodation, scenic spot tickets, restaurant food, etc., not only fully meet the personalized needs of tourists, also really into the dining at the same time, accommodation, transportation, travel, shopping and entertainment. Tourists can also share what they have seen, heard and learned during the journey through writing logs, taking photos and videos on social media, which can increase the fun of traveling and attract potential tourists to visit at the same time. When the tour is over, tourists can make comments and feedback on the quality of the tour on the tourism service platform. Inquiry, planning, sharing experience and evaluation and feedback are the functions of online intelligent tourism services most commonly used by tourists, and they are also the most critical parts of the tourism service platform. None of the three links is indispensable.

\section{Offline Smart Tourism Services}

Offline smart tourism services mainly include tour guide explanation, smart tour guide, intelligent guidance and other services. However, the services provided by different types of scenic spots should also be different. For example, tourists will not have too many requirements for the explanation service of scenic spots that are purely sightseeing. They only need to enjoy the experience by themselves to achieve the purpose of relaxation. However, for scenic spots with certain historical and cultural value, the guide's explanation is more important for tourists, so as to understand the function of rich knowledge of history. To avoid boring visitors with oral presentations, they can also be done using emerging technologies. For example, multimedia technology and virtual reality are used to present the exhibition, which can not only enhance tourists' experience and attract their interest, but also sublimate their emotions and affect their hearts (Guos, 2017).

\subsubsection{Big Data and Smart Tourism Marketing}

Tourism marketing is an external business activity that designs and develops tourism products according to the needs of target tourism market and provides tourists with effective products and services. In the era of big data, tourism marketers can extract such potentially valuable information as hot spots, off-season and regular changes in different periods of tourism destinations through big data, and conduct more accurate and personalized marketing on the basis of such information. According to the role of the marketer, it can be divided into tourism destination marketing and tourism enterprise marketing.

\section{Tourism Destination Marketing}

In the context of social big data, the government or tourism regulatory authorities can obtain a large amount of potentially valuable information through mining and analysis of online text information or wemedia tweets released by tourism destination websites, so as to guide the improvement of supporting service facilities or the development of relevant software and hardware. By analyzing and mining the information data of various new media platforms, the tourism demand level and motivation classification of tourism destinations can be discovered, so as to carry out the overall management planning for promoting the development of tourism destinations and improve the overall marketing level of tourism destinations.

In addition, tourism destination marketers can use big data to analyze information about tourists' preferences, needs and motivations. In this way, the management process can be optimized, resources can be allocated more scientifically, and tourists' personalized tourism needs and professional services can be satisfied from the perspective of tourists, so as to improve the reception capacity and service level of tourist destinations. How to use big data technology to explore tourism destination information has become a hot research topic of tourism marketing.

\section{Tourism Enterprise Marketing}

In the new era, tourism enterprise marketers can make tourism marketing more accurate and personalized with the help of big data platform. By collecting and analyzing the data and information of network users' visiting and searching in various fields, the group with tourism intention is screened out, so as to grasp the behavioral intention of potential tourists and accurately predict their motivations and preferences. Tourism 
enterprise operators should implement different marketing strategies when facing different tourist groups, so as to provide tourists with more targeted personalized services and implement more accurate marketing. For example, push specific relevant tourism websites or tourism information to target tourists in real time to stimulate their consumption impulse and drive tourism demand. In addition, through data processing and analysis, a lot of potential tourism customers can be discovered, and the behavioral trend information of potential tourists can be collected in time, and the tourism information that may be of interest can be pushed to them in time to stimulate tourism consumption.

\subsubsection{Big Data and Smart Tourism Management \\ 1. Tourist Flow Prediction and Warning}

Through the tourists' network access to search data, through the big data technology analysis and processing to understand the motivation of tourists and tourists focus on the hot tourist destinations and other information, so as to be able to estimate the number of tourists, do early warning of tourist flow and plan and implement the guide diversion work. According to the online ticket booking data information, we can roughly understand the tourist destination where tourists tend to concentrate, so that we can deploy the tourist flow warning and traffic dreading work in advance, reasonably guide the flow of tourists, and prepare an appropriate amount of tourism supporting service facilities.

\section{Online Public Opinion Supervision and Tourism Complaint Management}

Government departments and tourism-related organizations monitor the intelligence of public opinions on the Internet through big data technology, so as to timely discover netizens' criticisms and complaints and block and delete the wrong information on the Internet. Through the tourism supervision platform for realtime management of tourist complaints, timely handling of tourists' critical feedback and attention. In addition, a tourism public service website should be created to timely update and push the latest tourism policy news, travel safety tips, traffic jams or extreme weather warnings, etc.

\section{Tourism Resource Management}

Tourism resources are the carrier of tourism behavior. After the introduction of big data and other information technologies, the management of tourism resources in tourist attractions becomes more intelligent and informationized. For example, it can monitor the geographical and natural resources, facilities and equipment of scenic spots, and staff of scenic spots in real time. It can timely monitor and discover various factors that damage the resources and environment of scenic spots, and protect the environmental resources of scenic spots intelligently and efficiently (ZuoXiang \& Hu, 2011).

\section{Challenges in the Application of Big Data in Smart Tourism \\ 3.1. The Data Collection and Analysis System Needs to Be Optimized}

Every day, a large number of tourists search and browse on tourism websites or order online. At the same time, a large database can collect a large amount of tourists' visiting data, such as tourists' search records, browsing tourism products, submitted tourism orders and so on. These unprocessed data are numerous and messy, but the proportion of really valuable data is very small. Only through the mining and analysis of cloud computing big data and other tools can it have certain information value. This requires the establishment of certain norms in the process of data collection to minimize the processing of some meaningless data information.

It is necessary to make full use of the advantages and characteristics of big data to systematically integrate the collected data, so that valuable information and data can be timely analyzed and processed through big data, and provide decision-making Suggestions for operators of tourism enterprises. The cloud computing big data analysis system should be built on the tourism service information platform, so that the effective information and data of the tourism service platform are always in the scientific analysis and management, and the differentiated management system should be built for different data types, so as to promote the fine and scientific data analysis and processing.

\subsection{It Infrastructure Construction Needs to be Strengthened}

The development of smart tourism relies heavily on information science and technology. With the continuous development and progress of big data, many scenic spots begin to follow the general direction of tourism industry information development. With the help of the Internet of things platform, some scenic spots have realized the mutual connection between people, people and scenery, people and machine equipment, equipment and equipment. By using the big data cloud computing platform, it realizes the intelligent management and control of geographical and natural resources and tourists in scenic areas, promotes the intelligent management of scenic spots, and truly and efficiently protects the cultural heritage and natural resources of scenic spots. However, the development of most smart scenic spots still has a lot of room for improvement, and the construction of information infrastructure still needs to be improved. It is still a long way to go to fully realize the intelligent and thorough management of tourist scenic spots. 
1. Insufficient investment in basic hardware of smart scenic spot.

2. The intelligent monitoring system is not perfect.

3. Imperfect portal functions.

\subsection{Data Security is Facing Challenges}

The original intention of the application of big data technology is to let people enjoy the convenient services brought by information technology. Today, with the rapid transmission of information, our personal information is left in various database platforms unconsciously, and there are great security risks for personal privacy. The security of information data is not only an invasion of personal privacy, privacy disclosure may even endanger the safety of the person and property, bring potential instability factors to the society, and gradually become a problem that cannot be ignored to endanger the safety of the public (Xiang \& Tussyadiah, 2014). Open and Shared data resources are the prerequisite for the progress of big data technology, which conflicts with the privacy of information data. It is an urgent problem to ensure the security of personal information while making rational use of data in big data platform.

When big data technology is introduced into the tourism industry, data security risks cannot be avoided. Complete a tourist behavior would be in the hotel, the scenic area, transportation and other fields with personal data information, once the data is the bad man mining processing, it will greatly infringe the privacy rights of visitors, even threat to life and property safety, the involved tourism enterprises and even the tourism industry as a whole will have a negative impact.

\subsection{Disconnection of Online and Offline Services}

In the open Internet environment, online inquiry and ordering of goods has become an indispensable way of life for us, and the tourism industry has also gradually opened and rapidly developed online business. When consumers browse tourism products through web pages, they are first attracted by the pictures and text descriptions advertised by the products, and then decide whether to buy or not after consulting customer service or referring to the comments of others. When some tourists arrive at the tourist destination, they think that the real products they order online are inconsistent with the propaganda pictures, and then they think that online travel businesses have deceptive behaviors, which will greatly reduce the tourist's travel experience. This is because online tourism marketing and offline tourism services are not well connected.

\section{Promote the Active Application of Big Data in the Development of Smart Tourism 4.1. Attach Importance to Top-Level Construction}

First, the government and relevant departments need to take the overall situation into consideration, formulate unified big data standards, standardize the operation and implementation of big data collection, analysis and processing, do a good job in the basic guarantee of big data informatization tourism construction, improve the legislation of big data technology in the application process of smart tourism, and ensure the development effect of smart tourism.

Second, tourism enterprises should optimize and innovate their own operation and management mechanism, actively improve their technical level in line with the environment of modern emerging technology development (Guo \& Li, 2015) strengthen the coordinated and integrated development of their own enterprises and big data platform, and improve the degree of tourism informatization.

Third, the government and relevant tourism departments should pay attention to the application of big data in the infrastructure construction of smart tourism and ensure the introduction of major technologies in the informatization construction of tourism industry. Secondly, the government should allocate social resources scientifically to ensure the efficient use of information data, and build a big data platform to share data information.

\subsection{Attach Importance to the Construction of ICT Infrastructure}

One is to strengthen the construction of information intelligent facilities in tourist areas. The construction of intelligent scenic spots needs to strengthen the application of information and communication technology and the construction of intelligent facilities and equipment, so each scenic spot should invest in the basic data collection and analysis system, intelligent tour guide system, monitoring and management system, emergency security alarm system, etc., to ensure the normal operation of the intelligent system of tourist areas.

The second is to introduce the intelligent perception system of intelligent scenic spots (Li, 2017). Through all kinds of information sensing device can be directly grasp the visitor tickets, tourist consumption information of stream of people quantity, tourist movements, the scenic spot congestion, geography, natural resources, etc., in addition, to a comprehensive intelligent management system, introduced in scenic spots, including the entrances and exits, dangerous area of the scenic area, parking lots, etc., improve the scenic area management intellectualization and informatization construction, improve the scenic area construction of infrastructure services. 
Three is to establish the scenic spot emergency warning system. In coastal scenic areas near the water bank, the corresponding disaster emergency warning system should be built to guard against natural disasters such as typhoon and flood. The danger warning system should be built for scenic spots near mountain cliffs and other disasters such as landslides and debris flows.

Fourth, pay attention to the wisdom of tourists experience services. To ensure that tourists have a good experience is the core of the construction of smart scenic spots. After the construction of basic intelligent information infrastructure, tourist attractions should put the heart to serve tourists in the first place. From the perspective of tourists' psychology, we should provide more intimate and subtle services for tourists.

\subsection{Strengthen Data Security Management}

First, coordinate departments and institutions that have direct access to and use of relevant information data to create regulations on the standard use and management of confidential data. In the process of information data mining, analysis and processing, strict supervision and control should be in place. Let relevant staff sign a data confidentiality agreement to severely crack down on the act of leaking and stealing information and ensure the security of information and data.

Second, we need to strengthen technology and management. To constantly improve the technical level, improve the data management security protection system, for the emergence of vulnerabilities to timely repair. In terms of data management, it is necessary to determine the responsibilities and responsibilities of each person. The operation and maintenance of the database must be coordinated and managed by multiple personnel.

Third, the government needs to improve relevant supporting laws and regulations as soon as possible, formulate unified big data management application standards, strictly control the process of big data collection, analysis and processing, strictly prevent data leakage in data processing, and ensure the security of information and data.

\subsection{Pay Attention to the Training of Relevant Professionals}

First, pay attention to the cultivation of tourism big data talents' professional technical ability. Big data is a complex subject integrating computer science, information science, statistics, mathematics, management, etc. Zhang (2014) and it also requires certain professional qualities of tourism management, so it is necessary to cultivate a compound talent who is proficient in multi-disciplinary knowledge.

Second, pay attention to the cultivation of relevant personnel's professional ethics. Mainly involves the big data privacy security consciousness and the team cooperation consciousness. Big data experts should not only have a solid professional level, but also understand both data analysis and tourism industry.

Third, improve students' practical ability through school-enterprise research and learning cooperation. The school has a strong knowledge reserve and professional teachers, and the relevant enterprises can provide students with the opportunity to work in real combat, so that students can really apply what they have learned and get practical training. And then form a strong team with rich professional knowledge and practical experience in big data technology to promote the leapfrog development of smart tourism big data integration.

\section{Conclusion}

Smart tourism based on big data makes people's travel activities more convenient and intelligent, and gives new vitality to the tourism industry. Efforts should be made to improve the integration and application of big data technology in the smart tourism industry, and constantly improve the quality and level of tourism services (Ma, 2017). First of all, the government should increase investment in the informatization construction of tourism industry, improve the construction of supporting infrastructure, allocate data resources scientifically, and build a tourism big data platform. Technical experts should constantly improve the level of data mining and information technology capabilities to ensure data security; Relevant departments should make greater efforts to cultivate and introduce talents, and better promote the development of smart tourism industry with the help of all-round interdisciplinary talents of tourism big data.

At present, the introduction of big data technology into smart tourism industry has just started. How to promote the further development of smart tourism with the power of emerging information technology such as big data is still an important topic facing us, and we need to continue to explore and seek answers.

\section{References}

Chen, H. (2015). Application research of big data in smart tourism. Contemporary Economics, 2015(29), 38-39.

Dai, P. (2015). Study on tourism competitiveness evaluation of smart tourism cities -- study on opportunity BP neural network model: Guangxi Normal University.

Guo, X., \& Li, Y. (2015). Research review on intelligent tourism in China. Tourism BBS, 2015(6), 43-51.

Guos, L. (2017). Review of research on big data driving smart tourism development. Journal of Hebei Tourism Vocational College, $2017(2), 50-54$.

Jiang, Y., \& Chen, Z. (2018). Research on the development status and trend of smart tourism. Science and Education Guide (Electronic Edition), 2018(6), 210-210. 
Li, J. (2017). Investigation and analysis of Internet intelligent construction of yuncheng tourism scenic spot in the context of smart tourism. Foreign Trade and Economic Cooperation, 2017(7), 75-76.

Ma, Y. (2017). Research on the application of big data in smart tourism. Smart City, 2017(7), 107-107.

Tu, Q., \& Liu, A. (2014). Framework of smart tourism research and related progress in China. Paper presented at the International Conference on Management and Engineering (CME 2014). DEStech Publications.

Wang, D. (2014). Operation research of smart tourism within the framework of smart city: Ocean University of China.

$\mathrm{Wu}, \mathrm{Y} .(2015)$. Research on the construction of XS smart scenic spot: Zhengzhou University.

Xiang, Z., \& Tussyadiah, I. (2014). Information and communication technologies in Tourism 2014. Heidelberg: Springer.

$\mathrm{Xie}$, S. (2017). Discussion on the construction of intelligent tourism system in scenic spots. Cooperative Economy and Technology, 2017(23), 36-37.

Xing, X. (2019). China's TOP40 big data innovation scenario application service providers in 2018. Internet Weekly, 2019(4), 58-59.

Yang, X. (2015). Smart tourism reshapes new tourism experience in the era of big data. Oriental Corporate Culture, 2015(23), 235-235.

Zhang, M. (2014). Application of cuhk data technology in "smart city". Communications World, 2014(2), 5-7.

ZuoXiang, L., \& Hu, X. (2011). Exploration and application of medical data mining. China Rural Health Service Management, $2011(3), 268-270$ 